Document downloaded from:

http://hdl.handle.net/10251/148521

This paper must be cited as:

El Sayed, S.; Licchelli, M.; Martínez-Máñez, R.; Sancenón Galarza, F. (2017). Capped Mesoporous Silica Nanoparticles for the Selective and Sensitive Detection of Cyanide. Chemistry - An Asian Journal. 12(20):2670-2674. https://doi.org/10.1002/asia.201701130

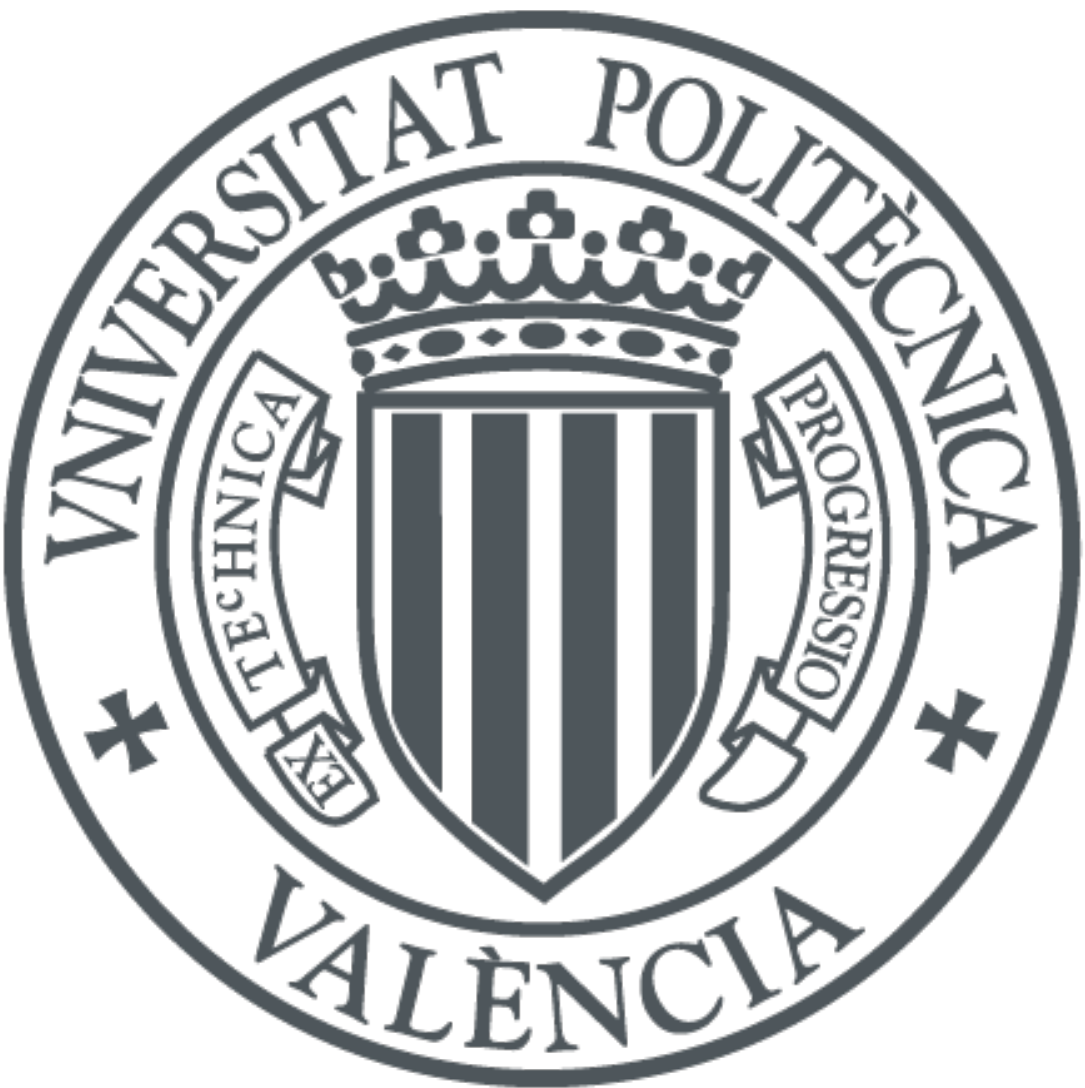

The final publication is available at

https://doi.org/10.1002/asia.201701130

Copyright John Wiley \& Sons

Additional Information 


\title{
Capped mesoporous silica nanoparticles for the selective and sensitive detection of cyanide
}

\author{
Sameh El Sayed, ${ }^{[a, b, c]}$ Maurizio Licchelli, ${ }^{[d] \star}$ Ramón Martínez-Máñez ${ }^{[a, b, c] \star}$ and Félix Sancenón ${ }^{[a, b, c]}$
}

\begin{abstract}
The development of easy and affordable methods for the detection of cyanide is of great significance due to the high toxicity of this anion and the potential risks associated with its pollution. Herein, optical detection of cyanide in water has been achieved by using a hybrid organic-inorganic nanomaterial. Mesoporous silica nanoparticles were loaded with $\left[\mathrm{Ru}(\mathrm{bipy})_{3}\right]^{2+}$, functionalized with macrocyclic Nickel(II) complex subunits, and capped with a sterically hindering anion (hexametaphosphate). Cyanide selectively induces demetallation of Nickel(II) complexes and the removal of capping anions from the silica surface, allowing the release of the dye and the consequent increase of fluorescence intensity. The response of the capped nanoparticles in aqueous solution is highly selective and sensitive towards cyanide with a limit of detection of $2 \mu \mathrm{M}$.
\end{abstract}

Anions are vital partners of our biological system, but their abnormal concentrations always cause diseases for humans. One of the most toxic anions is cyanide. Concentrations of cyanide in the $0.5-3.5 \mathrm{mg} / \mathrm{kg}$ body weight interval are lethal to humans. ${ }^{1}$ It is known that, at these concentrations, cyanide strongly binds to the cytochrome $\mathrm{c}$ active sites resulting in inhibition of cellular respiration ${ }^{2}$ with subsequent central nervous system damage. ${ }^{3}$ Taking into account these facts it is not strange that cyanide was used as chemical warfare agent. ${ }^{4}$ Besides natural sources, cyanide is widely used in industry e.g. metal mining processes, organic chemical industries, iron and steel plants and wastewater treatment facilities. ${ }^{5,6}$ All these industries can be sources of water and environmental contaminations with cyanide. At this respect, the maximum permissive concentration of cyanide in drinking water is set at $1.9 \mu \mathrm{M}$ by the World Health Organization $(\mathrm{WHO}),{ }^{7}$ while in industrial effluents this level is also strictly regulated to be below $1 \mu \mathrm{M} .^{8}$

In consideration of the potential risks associated with cyanide pollution, easy and affordable detection methods for this

[a] Dr. S. El Sayed, Prof. R. Martínez-Máñez, Dr. F. Sancenón Departamento de Química

Universitat Politécnica de València

Camino de Vera s/n, 46022, Valencia, Spain

E-mail: rmaez@qim.upv.es

[b] Dr. S. El Sayed, Prof. R. Martínez-Máñez, Dr. F. Sancenón Instituto Interuniversitario de Investigación de Reconocimiento Molecular y Desarrollo Tecnológico (IDM)

Universitat Politécnica de València-Universitat de València

[c] Dr. S. El Sayed, Prof. R. Martínez-Máñez, Dr. F. Sancenón CIBER de Bioingeniería, Biomateriales y Nanomedicina (CIBERBBN)

[d] Prof. M. Licchelli

Dipartimento di Chimica

Università di Pavia

via Taramelli 12, I-27100 Pavia, Italy

E-mail: maurizio.licchelli@unipv.it

Supporting information for this article can be found under: $x x x x x x x x$ anion are of great concern. Different methods involving titrimetric, colorimetric, and electrochemical procedures are currently used for cyanide detection. ${ }^{9}$ However, these methods are sometimes expensive, time consuming and require complex instrumentation. Recently, as a clear alternative, the use of optical chemical sensors and probes for the detection and quantification of cyanide anion has attracted great attention due to their easy synthesis and handling, the use of quite common instrumentation (UV-visible spectrophotometer or fluorimeter), and the high degree of sensitivity achieved. ${ }^{10}$ In spite of these promising features, these chemosensors and probes have several drawbacks such as poor water solubility (that partially precludes their application for monitoring real samples), low selectivity and a non-immediate response (considering that most of the described probes takes advantage of the nucleophilic character of cyanide anion). ${ }^{11}$ Very recently, as an alternative to molecular probes, the use of capped hybrid organic-inorganic nanomaterials in sensing protocols have been described. ${ }^{12,13}$ These hybrid materials are mainly composed by three components, namely: (i) an inorganic porous support, (ii) a dye/fluorophore loaded inside the pores and (iii) molecular or supramolecular assemblies grafted onto the external surface of the solid. In these sensing materials the external grafted molecules control mass transport, from the inner of the pores to the bulk solution, after coordination/reaction with a certain analyte. ${ }^{14}$ One of the most interesting features of these gated materials is the potential amplification effect taking into account that few analyte molecules could induce the release of a relatively high amount of entrapped dye/fluorophore..$^{15}$

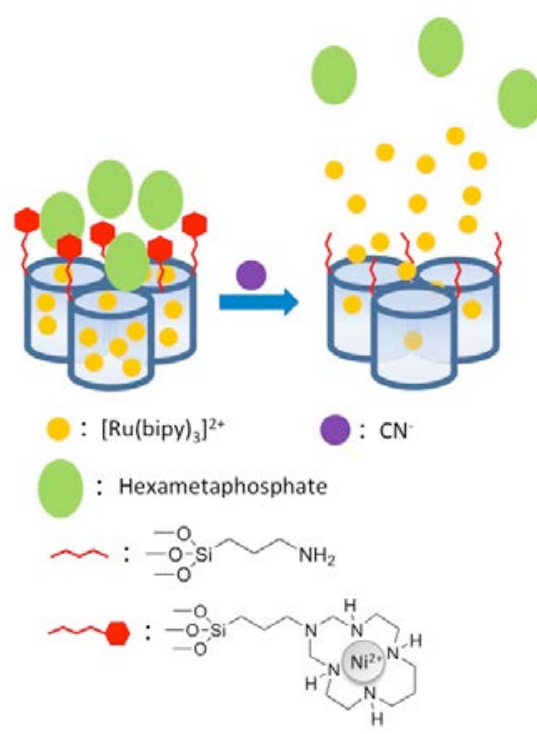

Scheme 1. Schematic representation of the sensing mechanism of solid NP3 in the presence of cyanide. 
Bearing in mind our interest in the applications of gated materials in sensing protocols, we report herein the design of mesoporous silica nanoparticles functionalized with a $\mathrm{Ni}^{\prime \prime}$ complex, capped with hexametaphosphate anion and the use of such nanodevice for the selective and sensitive detection of cyanide in water. Our proposed sensing protocol is shown in Scheme 1. MCM-41 mesoporous silica nanoparticles of ca. 100 $\mathrm{nm}$ diameter were selected as inorganic scaffold and the pores loaded with $\left[\mathrm{Ru}(\mathrm{bipy})_{3}\right]^{2+}$ dye. Then, the external surface of the loaded scaffold was functionalized with a Nill-macrocyclic complex (solid NP2). Finally, the pores were capped upon addition of hexametaphosphate anion (solid NP3) through electrostatic/coordinative interactions with the grafted $\mathrm{Nill}$ complex. The signalling paradigm relies on a demetallation of the Nill complex induced by cyanide anion, which would uncap the pores with subsequent dye release. This paradigm has been recently used by us to prepare gated materials for the selective detection of hydrogen sulfide. ${ }^{16}$ Besides, and as far as we know, NP3 is the first capped material used for the selective and sensitive detection of cyanide anion.

In a first step, MCM-41 mesoporous nanoparticles were prepared according to a standard procedure. Then, the pores of the nanoparticles were loaded with $\left[\mathrm{Ru}(\mathrm{bipy})_{3}\right]^{2+}$ by stirring a suspension of the calcined nanoparticles in an acetonitrile solution of the dye. Thereafter, the external surface of the loaded silica nanoparticles was functionalized by a modified twostep literature procedure: ${ }^{17}$ (i) treatment with (3aminopropyl)triethoxysilane yielding solid NP1; (ii) "template" reaction $^{18}$ of amino-functionalised NP1 with [Ni"(2,3,2-tet)] ${ }^{2+}$ (2,3,2-tet $=\mathrm{N}, \mathrm{N}^{\prime}$-Bis(2-aminoethyl)propane-1,3- diamine) in the presence of formaldehyde and triethylamine, yielding nanoparticles functionalized with $\mathrm{Nil}^{\text {"-azacyclam }}{ }^{19}$ subunits (NP2) The final solid NP3 was obtained by stirring of NP2 with hexametaphosphate in water (see Scheme 1 and Supporting Information for details).

Table 1. Content ( $\alpha$ ) of anchored complex and dye in hybrid materials.

\begin{tabular}{lccc}
\hline Solid & $\begin{array}{l}\alpha_{\text {complex 3 }} \\
{\left[\mathrm{mmol} \mathrm{g}^{-1} \mathrm{SiO}_{2}\right]}\end{array}$ & $\begin{array}{l}\alpha_{\text {dye }} \\
{\left[\mathrm{mmol} \mathrm{g}^{-1} \mathrm{SiO}_{2}\right]}\end{array}$ & $\begin{array}{l}\alpha_{\text {m-phosphate }} \\
{\left[\mathrm{mmol} \mathrm{g}^{-1} \mathrm{SiO}_{2}\right]}\end{array}$ \\
\hline NP2 & 0.107 & 0.37 & - \\
NP3 & 0.106 & 0.34 & 0.05 \\
\hline
\end{tabular}

The starting MCM-41 nano-sized scaffold and NP3 solid were characterized using standard procedures (see Supporting Information). Powder X-ray diffraction (PXRD) and transmission electron microscopy (TEM) measurements carried out on the MCM-41 nanoparticles showed the presence of a mesoporous structure that persisted in solid NP3 regardless loading with dye, functionalization with $\mathrm{Ni}^{\text {Il }}$ complex, and capping with hexametaphosphate anion. TEM images of calcined MCM-41 and NP3 nanoparticles are reported Figure 1 and show that NP3 preserved the spherical shape of the calcined MCM- 41 starting material, and a very similar average diameter of $99 \pm 6 \mathrm{~nm}$. On the other hand, thermogravimetric and elemental analysis were used to determine the contents of Ru(bipy) $3_{3}{ }^{2+}$, nickel(II) complex, and hexametaphosphate in solids NP2 and NP3 (see Table 1). Main structural characteristics for MCM-41 and NP3 such as surface area, particle diameter, pore volume and size were also determined (see Table 2 and Supporting Information).

Table 2. Main structural properties of nano-sized materials determined by TEM, PXRD and $\mathrm{N}_{2}$ adsorption analysis..

\begin{tabular}{lllll}
\hline Sample & $\begin{array}{l}\text { Particle } \\
\text { diameter } \\
(\mathrm{nm})\end{array}$ & $\begin{array}{l}\text { Surface } \\
\text { area, SBET } \\
\left(\mathrm{m}^{2} \mathrm{~g}^{-1}\right)\end{array}$ & $\begin{array}{l}\text { Pore } \\
\text { Volume }^{[\mathrm{b}]} \\
\left(\mathrm{cm}^{3} \mathrm{~g}^{-1}\right)\end{array}$ & $\begin{array}{l}\text { Pore } \\
\text { size } \\
(\mathrm{nm})\end{array}$ \\
\hline MCM-41 & $95.0 \pm 5.0$ & 970.5 & 0.89 & 2.49 \\
NP3 & $99.0 \pm 6.0$ & 218.5 & 0.22 & - \\
\hline
\end{tabular}

[a] Measured by TEM. [b] Pore volumes and pore sizes associated only with intra-particle mesopores. [c] Pore size estimated by using the $\mathrm{BJH}$ model applied to the adsorption branch of the isotherm.
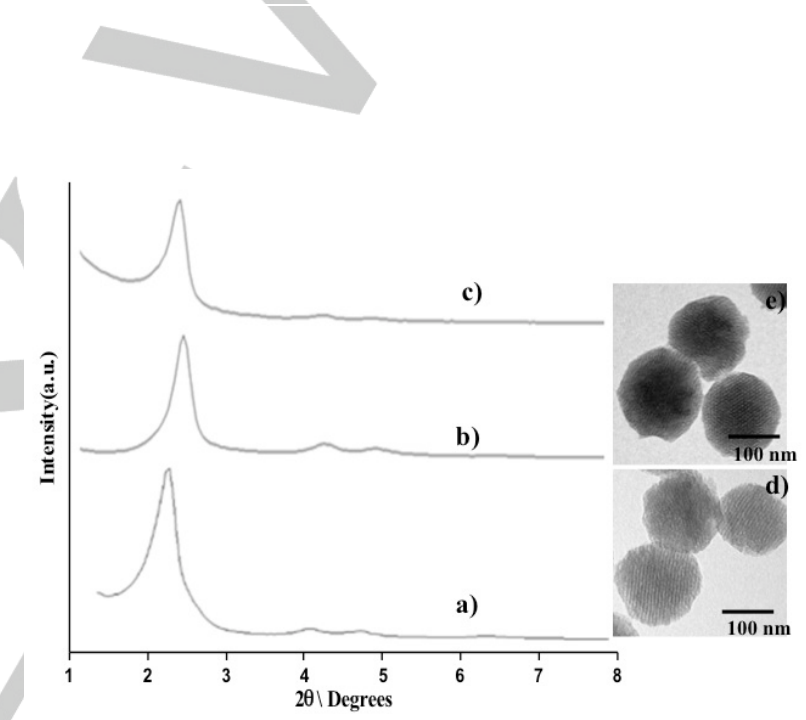

Figure 1. Left: powder X-ray patterns of the solids (a) MCM-41 as synthesized (b) calcined MCM-41 and (c) solid NP3. Right: TEM images of (d) calcined MCM-41 sample and (e) solid NP3.

After characterization of hybrid materials, the sensing features of solid NP3 in the presence of selected anions were tested. For this purpose, in a typical assay, $1 \mathrm{mg}$ of NP3 was suspended in $2 \mathrm{~mL}$ of buffered solution (pH 7.5, HEPES $10 \mathrm{mM}$ ) in absence (control) and in the presence of cyanide anion. In both cases suspensions were stirred at room temperature and, at scheduled times (up to 6 hours), aliquots were taken, centrifuged, and dye delivered to the bulk solution was detected by monitoring the emission band of $\left[\mathrm{Ru}(\text { bipy })_{3}\right]^{2+}$ at $610 \mathrm{~nm}$ (upon excitation at $451 \mathrm{~nm}$ ). In the absence of cyanide anion, a negligible dye release was observed due to a thight pore closure as a consequence of the strong interaction between hexametaphosphate anion and the grafted $\mathrm{Ni}$ "-macrocyclic complex. Conversely, in the presence of cyanide anion, a remarkable $\left[\mathrm{Ru}(\mathrm{bipy})_{3}\right]^{2+}$ delivery was observed even after just $45 \mathrm{~min}$. The release of $\left[\mathrm{Ru}(\text { bipy })_{3}\right]^{2+}$ dye from solid NP3 in the presence of cyanide anion is directly related with the demetallation of $\mathrm{Nill}$-azacyclam complexes, the consequent 
decomposition of the macrocyclic moieties, ${ }^{19}$ and the removal of bulky anions. This demetallation process is highly favoured taking into account the strong stability constant for the formation of $\left[\mathrm{Ni}(\mathrm{CN})_{4}\right]^{2-}$ complex $\left(\log \beta_{4}=30.5 \text { at } 25^{\circ} \mathrm{C}\right)^{20}$ in water when compared to that of the macrocyclic complex $\left(\log \mathrm{K}_{\mathrm{f}}=22.2\right.$ at $25{ }^{\circ} \mathrm{C}$ for $\left[\mathrm{Nil}\left(\right.\right.$ cyclam)] ${ }^{2+}$ taken as reference). ${ }^{20}$ In order to confirm the demetallation process, energy dispersive $\mathrm{X}$-ray spectroscopy (EDX, $20 \mathrm{kV}$ ) was used to determine $\mathrm{Ni}$ and $\mathrm{P}$ content in the nanoparticles before and after cyanide-induced pore opening and dye release. In the initial NP3 nanoparticles EDX measurements showed values of weight percentage of $0.59 \%$ and $4.88 \%$ for $\mathrm{Ni}$ and $\mathrm{P}$ respectively. The presence of $\mathrm{Ni}$ and $P$ in the surface of NP3 nanoparticles indicated the proper grafting of the $\mathrm{Ni}$ "-azacyclam complexes and the further capping of the pores with hexametaphosphate anion. As clear contrast, a marked decrease in $\mathrm{Ni}$ (weight percentage of $0.02 \%$ ) and $\mathrm{P}$ (weight percentages of $0 \%$ ) content in the final solid (after pore opening in the presence of cyanide anion) was measured. These reductions in $\mathrm{Ni}$ and $\mathrm{P}$ contents are clearly ascribed to a cyanide-induced demetallation process with the subsequent detachment of hexametaphosphate anion, pore opening and dye release. Besides, the ruthenium content (as weight percentage) also decreased from 0.54 (in NP3 nanoparticles) to 0.14 (nanoparticles after reaction with cyanide anion and proper washing) as a result of pore uncapping and $\left[\mathrm{Ru}(\mathrm{bipy})_{3}\right]^{2+}$ complex delivery.

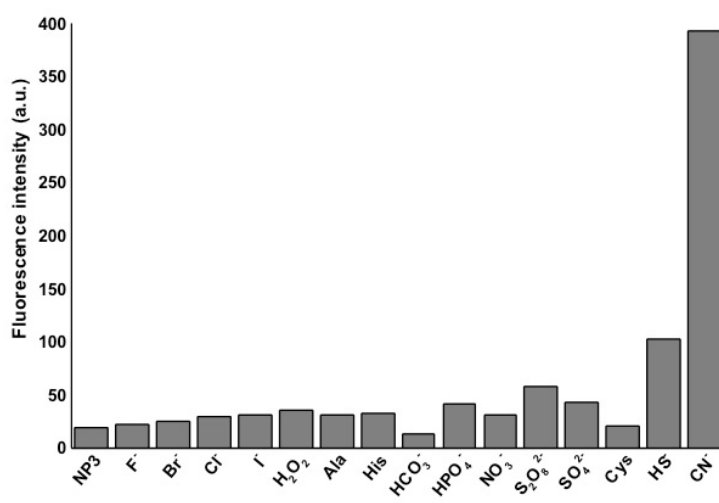

Figure 2. Fluorescence intensity at $610 \mathrm{~nm}$ of $\left[\mathrm{Ru}(\mathrm{bipy})_{3}\right]^{2+}$ dye released from NP3 (HEPES $10 \mathrm{mM}$ at $\mathrm{pH} 7.5$ ) after $6 \mathrm{~h}$ from addition of selected anions, amino acids and oxidants (1 mM)

Table 3. Determination of cyanide spiked in tap water samples using NP3.

\begin{tabular}{llll}
\hline Sample & $\begin{array}{l}\mathrm{CN}^{-} \text {spiked } \\
(\mu \mathrm{M})\end{array}$ & $\begin{array}{l}\mathrm{CN}^{-} \text {determined } \\
(\mu \mathrm{M})\end{array}$ & $\begin{array}{l}\text { Recovery } \\
(\%)\end{array}$ \\
\hline $\mathbf{1}$ & 4.0 & $3.41 \pm 0.44$ & 85 \\
$\mathbf{2}$ & 6.0 & $5.34 \pm 1.87$ & 89 \\
$\mathbf{3}$ & 12.0 & $10.93 \pm 2.93$ & 91 \\
\hline
\end{tabular}

Besides, the crucial role played by $\mathrm{Ni}^{\prime \prime}$ cation in the capping protocol was demonstrated using solid NP1 (loaded with $\left[\mathrm{Ru}(\mathrm{bipy})_{3}\right]^{2+}$ dye and functionalized in its outer surface with aminopropyl moieties). With solid NP1 none of the anions tested (including hexametaphosphate) were able to block the pores and to inhibit $\left[\mathrm{Ru}(\text { bipy })_{3}\right]^{2+}$ release.

On the other hand, the selectivity of NP3 nanoparticles toward cyanide was assessed by testing the controlled release performance in the presence of other anions $\left(\mathrm{HS}^{-}, \mathrm{F}^{-}, \mathrm{Cl}^{-}, \mathrm{Br}^{-}, \mathrm{I}^{-}\right.$, $\mathrm{HPO}_{4}^{-}, \mathrm{NO}_{3}{ }^{-}, \mathrm{HCO}_{3}{ }^{-}, \mathrm{SO}_{4}{ }^{2-}$ ), selected amino acids (Ala, His, Cys), and oxidants $\left(\mathrm{H}_{2} \mathrm{O}_{2}\right.$ and $\left.\mathrm{S}_{2} \mathrm{O}_{8}{ }^{2-}\right)$. Figure 2 shows the emission of $\left[\mathrm{Ru}(\mathrm{bipy})_{3}\right]^{2+}$ dye at $610 \mathrm{~nm}$ in the solution after addition of selected species (1 mM) to buffered suspension of NP3. As it can be seen, none of the tested chemicals were able to induce cargo delivery, pointing toward a highly selective response of NP3 solid toward cyanide anion. We recently reported hexametaphosphate-capped nanoparticles functionalized with a $\mathrm{Cu}^{\prime \prime}$ macrocyclic complex, which were selectively uncapped only upon hydrogen sulfide addition. ${ }^{16,21}$ Previous and current results indicate that the selectivity of the hexametaphosphate-capped nanoparticles can be properly addressed by changing the metalmacrocyclic subunits grafted on their surface. In particular, the presence of $\mathrm{Cu}^{\text {"l }}$ complexes make nanoparticles to respond selectively to hydrogen sulphide, whereas on changing to $\mathrm{Nill}$ the uncapping process is only observed with cyanide.

The controlled release performance of NP3 was tested upon addition of increasing quantities of cyanide and using the same protocol described above. Results depicted in Figure 3 show a clear correlation between cyanide concentration and the amount of released $\left[\mathrm{Ru}(\mathrm{bipy})_{3}\right]^{2+}$. This correlation agrees with the abovementioned uncapping mechanism involving a demetallation reaction and the formation of $\left[\mathrm{Ni}(\mathrm{CN})_{4}\right]^{2-}$ complex. From the titration profile shown in Figure 3 a limit of detection for cyanide of $2 \mu \mathrm{M}$ was measured. As cited in the introduction one powerful characteristic of analyte-induced uncapping protocols in gated solids is the possible presence of signal amplification features. In particular, for solid NP3, it was confirmed that the presence of one cyanide ion results in the release of ca. 180 molecules of $\left[\mathrm{Ru}(\text { bipy) }]^{2+}\right.$ dye.

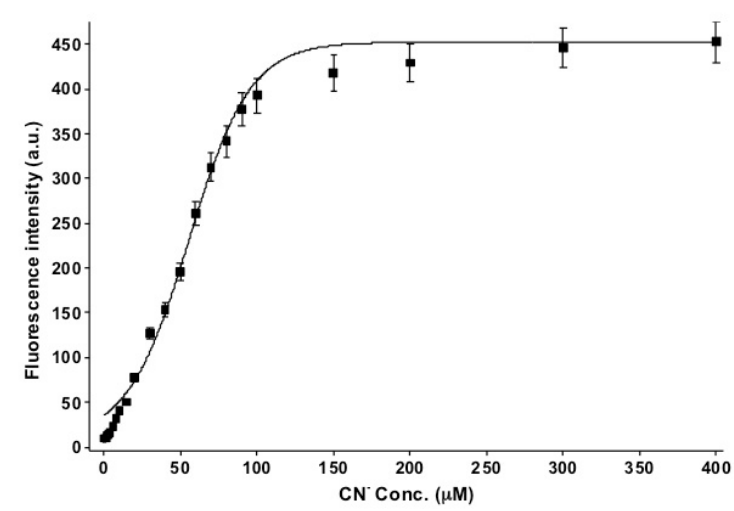

Figure 3. Calibration curve of $\left[\mathrm{Ru}(\text { bipy) }]_{3}\right]^{2+}$ dye released from NP3 (HEPES 10 $\mathrm{mM}, \mathrm{pH} 7.5$ ) upon addition of increasing quantities of cyanide. 
Finally, in order to test the possible applicability of NP3 nanoparticles for cyanide sensing in real environments, tap water was spiked with known amounts of this anion and the concentration determined using the standard addition method. The obtained results, shown in Table 3, indicate that NP3 was able to detect cyanide with recovery ratios ranging from 85 to $91 \%$.

In conclusion, we report in this communication a new hybrid organic-inorganic material made by silica nanoparticles loaded with $\left[\mathrm{Ru}(\mathrm{bipy})_{3}\right]^{2+}$ dye, functionalized with a Ni"-macrocyclic complex and capped with bulky hexametaphosphate anion. Among all the tested species, only cyanide is able to induce pore opening and dye release. The observed delivery can be clearly ascribed to a cyanide-induced demetallation reaction with a consequent detachment of hexametaphosphate anion from the nanoparticles surface. The response of the capped nanoparticles is highly selective and sensitive to cyanide anion with a limit of detection of $2 \mu \mathrm{M}$. Moreover, the capped nanoparticles have been used to detect cyanide in tap water with high recovery rates.

\section{Acknowledgements}

We thank the Spanish Government (projects MAT2015-64139C4-1-R and AGL2015-70235-C2-2-R (MINECO/FEDER, UE)) and the Generalitat Valenciana (project PROMETEOII/2014/047) for support.

\section{Conflict of interest}

The authors declare no conflict of interest.

Keywords: optical detection $\bullet$ hybrid materials $\bullet$ mesoporous silica nanoparticles $\bullet$ cyanides $•$ macrocyclic ligands $\bullet$

[1] G. D. Muir Hazards in Chemical Laboratory, The Royal Chemical Society, London, 1977.

[2] Y. Chen, L. J. Deterding, K. B. Tomer, R. P. Mason, Biochemistry 2000, 39, 4415-4422.

[3] T. Tylleskar, W. P. Howlett, H. T. Rwiza, S. Aquilonius, E. Stalberg, B. Linden, A. Mandahl, H. C. Larsen, G. R. Brubaker, H. Rosling, J. Neurol., Neurosurg. Psychiatry 1993, 56, 638-643.

[4] J. D. Johnson, T. L. Meisenheimer, G. E. Isom, Toxicol. Appl. Pharmacol. 1986, 84, 464A.

[5] K. W. Kulig Cyanide Toxicity, U.S. Department of Health and Human Services, Atlanta, GA, 1991.
[6] J. Jiang, X. Wang, W. Zhou, H. Gao, J. Wu, Phys. Chem. Chem. Phys 2002, 4, 4489-4494.

[7] WHO, Guidelines for drinking-water quality, World Health Organisation Geneva, Switzerland, 2011, p. 342

[8] E. Gail, S. Gos, R. Kulzer, J. Lorosch, A. Rubo, M. Sauer, R. Kellens, J. Reddy, N. Steier, W. Hasenpusch Cyano Compounds, Inorganic, in Ullmann's Encyclopedia of industrial Chemistry, Wiley VCH, New York, 2011.

[9] a) Standard Methods for the Examination of Water and Wastewater, 22nd Edition, American Public Health Association, Washington DC USA, 2012; b) T. Suzuki, A. Hioki, M. Kurahashi, Anal. Chim. Acta 2003, 476, 159-165; c) A. Safavi, N. Maleki, H. R. Shahbaazi, Anal. Chim. Acta 2004, 503, 213-221; d) V. K. Rao, S. R. Suresh, N. B. S. N. Rao, P. Rajaram, Bull. Electrochem. 1997, 13, 327-329.

[10] a) F. Wang, L. Wang, X. Chen, J. Yoon, Chem. Soc. Rev. 2014, 43 4312-4324; b) W. C. Lin, S. K. Fang, J. W. Hu, H. Y. Tsai, K. Y. Chen Anal. Chem. 2014, 86, 4648-4652; c) L. Wang, L. Zhu, D. Cao, New J. Chem. 2015, 39, 7211-7218; d) P. Singh, L. S. Mittal, S. Kumar, G. Bhargava, S. Kumar, J. Fluoresc. 2014, 24, 909-915; e) K. Hong, H. Yoon, W. Jang, Chem. Commun. 2015, 51, 7486-7488; f) R.M.F. Batista, E. Oliveira, S.P.G. Costa, C. Lodeiro, M.M.M. Raposo, Supram Chem. 2014, 26, 71-80; g) P. A. Gale, C. Caltagirone, Chem. Soc. Rev. 2015, 44, 4212-4227

[11] a) Y, Shiraishi, M. Nakamura, T. Kogurea, T. Hirai, New J. Chem. 2016 40, 1237-1243; b) K. S. Bejoymohandas, A. Kumar, S. Sreenadh, E. Varathan, S. Varughese, V. Subramanian, M. L. P. Reddy, Inorg. Chem 2016, 55, 3448-3461.

[12] a) F. Sancenón, L. Pascual, M. Oroval, E. Aznar, R. Martínez-Máñez. ChemistryOpen 2015, 4, 418-437; b) S. El Sayed, LI. Pascual, M. Licchelli, R. Martínez-Máñez, S. Gil, A. M. Costero, F. Sancenón., ACS Appl. Mater. Interfaces 2016, 8, 14318-14322; c) C. Coll, A. Bernardos, R. Martínez-Máñez, F. Sancenón, Acc. Chem. Res., 2013, 46, 339-349.

[13] M. W. Ambrogio, C. R. Thomas, Y.-L. Zhao, J. I. Zink, J. F. Stoddart Acc. Chem. Res. 2011, 44, 903-913.

[14] E. Aznar, M. Oroval, LI. Pascual, J. R. Murguía, R. Martínez-Máñez, F. Sancenón, Chem. Rev. 2016, 116, 561-718.

[15] a) LI. Pascual, S. El Sayed, R. Martínez-Máñez, A. M. Costero, S. Gil, P. Gaviña, F. Sancenón.,Org. Lett. 2016, 18, 5548-5551; b) S. E Sayed, C. Giménez, E. Aznar, R. Martínez-Máñez, F. Sancenón, M. Licchelli, Org. Biomol. Chem., 2015,13, 1017-1021.

[16] S. El Sayed, M. Milani, M. Licchelli, R. Martínez-Máñez, F. Sancenón, Chem. Eur.J. 2015, 21,7002-7006

[17] S. Attia, A. Shames, I. Zilbermann, G. Goobes, E. Maimona, Dan Meyerstein, Dalton Trans. 2014, 43, 103-110

[18] a) L. Fabbrizzi, M. Licchelli, A.M.M. Lanfredi, O. Vassalli, F. Ugozzoli Inorg. Chem. 1996, 35, 1582-1589; b) M. Boiocchi, M. Licchelli, M. Milani, A. Poggi, D. Sacchi, Inorg. Chem. 2015, 54, 47 - 58.

[19] L. Fabbrizzi, M. Licchelli, L. Mosca, A. Poggi, Coord. Chem. Rev. 2010 254, 1628-1636.

[20] F. H. Hinz, D. W. Margerum, Inorg. Chem. 1974, 13, 2941-2949.

[21] S. El Sayed, M. Milani, C. Milanese, M. Licchelli, R. Martínez-Máñez, F. Sancenón, Chem. Eur. J. 2016, 22, 13935-13945. 


\section{Entry for the Table of Contents}

\section{COMMUNICATION}

Mesoporous silica nanoparticles loaded with Ru(bipy) ${ }_{3}{ }^{2+}$, functionalized with $\mathrm{Ni}$ " macrocyclic complex subunits, and capped with a bulky anion (hexametaphosphate) were used to selectively and sensitively detect cyanide in water.

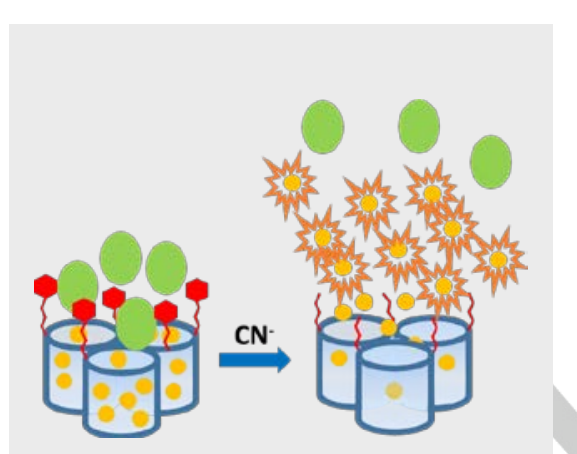

S. El Sayed, M. Licchelli. *R. MartínezMáñez* and F. Sancenón.

Page No. - Page No.

Capped mesoporous silica nanoparticles for the selective and sensitive detection of cyanide. 